\title{
Special issue:

\section{Constraint manipulation as a feasible strategy for gait alteration and intervention: a scoping review}

\author{
ANA M. F. BARELA ${ }^{1}$ | GABRIELA L. GAMA ${ }^{1}$ | MELISSA L. CELESTINO1 \\ 1 Institute of Physical Activity and Sport Sciences, Cruzeiro do Sul University, São Paulo, SP, Brasil.
}

Correspondence to: Profa. Dra. Ana Maria Forti Barela. Universidade Cruzeiro do Sul. Rua Galvão Bueno, 868. Liberdade, São Paulo, SP, Brasil, $01506-000$.

email:ambarela@gmail.com

https://doi.org/10.20338/bjmb.v15i5.263

\section{HIGHLIGHTS \\ - Surface and amount of body weight unloading \\ modify gait patterns. \\ - Body weight support systems enable \\ individuals with gait impairment to walk. \\ - Gait with body weight unloading on the \\ ground better resembles daily-life gait.

$\begin{array}{ll}\text { ABBREVIATIONS } \\ \text { BWS } & \text { Body weight support } \\ \text { CP } & \text { Cerebral palsy } \\ \text { GMFCS } & \text { Gross Motor Function } \\ & \text { Classification System } \\ \text { GMFM } & \text { Gross Motor Function Measures } \\ \text { LEM } & \begin{array}{l}\text { Laboratório para Estudos do } \\ \text { Movimento }\end{array}\end{array}$

PUBLICATION DATA

Received 15102021

Accepted 29112021

Published 01122021

\begin{abstract}
In this paper, we describe general information regarding the use of the partial body weight support (BWS) paradigm as a strategy to manipulate constraints during walking by individuals with and without gait impairments. We present two overground BWS systems implemented by our research group and the main studies that have been conducted so far. Non-disabled young adults, individuals with stroke, and children with cerebral palsy were considered in our investigations. Gait assessment with different amounts of body weight unloading on both the treadmill and the ground, as well as gait training protocols with BWS on these surfaces, were conducted, and general results are reported. Based on our investigations, we suggest that the use of a BWS system on a treadmill and on the ground, as a strategy for manipulating constraints, enables individuals with gait impairment to walk. More importantly, professionals in the field of gait rehabilitation can carry out training protocols throughout the manipulation of implements that assist walking, such as using a harness connected to a structure.
\end{abstract}

KEYWORDS: Body weight unloading | Walking | Non-disabled adults | Stroke | Cerebral palsy

\section{INTRODUCTION}

Following the onset of upright bipedal locomotion, walking is the preferred mode of locomotion adopted by human beings to cover short distances. This fundamental motor skill allows independence and autonomy in searching and interacting with the near environment and other individuals and, consequently, persuades motor, social, and cognitive development. On the other hand, it is well established that internal and external factors influence gait, $1^{*}$ such as age, $2,3,4$ motor and/or neurological disability, ${ }^{5,6,7}$ and environmental context.8,9,10 Taken together, it is possible to discern the importance of investigating gait, and more specifically walking, towards improving gait capabilities through strategies of intervention for those with gait impairment.

A promising approach to investigate walking derives from the constraints

\footnotetext{
* It is important to note that although most people tend to use the terms "gait" and "walking" interchangeably, there is a difference. According to Whittle (2007), gait refers to the "manner or style of walking, rather than the walking process itself" (p. 48), and it comprises walking, running, galloping, and more. Walking, on the other hand, is the motor skill itself.

${ }^{1}$ Whittle M. Gait analysis: an introduction. 4th ed. Ediburgh: Butterworth Heinemann; 2007.
}

\begin{tabular}{|c|c|c|c|c|c|}
\hline $\begin{array}{l}\text { Barela, Gama, } \\
\text { Celestino }\end{array}$ & 2021 & VOL.15 & N.5 & https://doi.org/10.20338/bjmb.v15i5.263 & 416 of 428 \\
\hline
\end{tabular}


perspective, envisioned by Newel. ${ }^{11}$ Overall, constraint can be understood as a feature that outlines the execution of movements. Newell ${ }^{11}$ suggested that the control and coordination pattern for the performance of any motor skill emerge from the interaction among three categories of constraint, namely organismic (the performer's physical and cognitive characteristics), environmental (the context where the motor skill is performed), and task (the motor task itself, including goals, rules, and tools that specify the output) constraints. ${ }^{11}$ It is important to note that the impact of constraints from these categories on the control and coordination pattern varies accordingly. In this way, individual differences may lead to different patterns of coordination and control for the same set of constraints. Similarly, changes in environmental differences may lead to different patterns of coordination and control by the same individual.

The performance of any motor skill, such as walking, is influenced by the physical and cognitive characteristics of the performer, the motor skill itself, and the context in which the motor skill is performed. Therefore, the main goal of this paper is to present general information regarding the investigations we have conducted recently using the constraints as the background to investigate gait. We manipulated the constraints to examine practicable strategies for gait intervention, as follows.

\section{"MANIPULATING" CONSTRAINTS}

A strategy we adopted in some of our gait investigations is the employment of body weight support (BWS) systems. The rationality that underlies this strategy originated from experiments in cats with a complete spinal cord injury, ${ }^{12,13}$ and subsequently employed in humans. ${ }^{14,15,16} \mathrm{~A}$ BWS system alleviates the gravitational forces acting on the lower limbs ${ }^{17}$ and, consequently, reduces the load that should be overcome by the performer, ${ }^{18,19}$ which in turn might facilitate walking performance. In addition, the use of a BWS system promotes safety (that is, low fall risk) and might favor postural alignment and balance. ${ }^{14}$

Usually, a BWS system consists of a treadmill and a mounting frame with an apparatus that mechanically supports the individual wearing a harness (Figure 1); several investigations have been conducted using BWS on a treadmill in different populations. ${ }^{20,21,22,23,24}$ The use of a treadmill combined with a BWS presents benefits and drawbacks. For example, a treadmill can be fitted in a small space, and its speed can be precisely controlled as the performer practices numerous steps repetitively and consistently. However, if we consider that walking on a treadmill is different from walking on the ground, $25,26,27$ it could be difficult to transfer the acquired skills from a treadmill training protocol to the ground, which is the surface used on a daily basis. Based on these issues, we questioned whether the use of a BWS system on the ground would be more appropriate and feasible than a treadmill (mainly for individuals with gait impairment) for overall gait performance intervention. Furthermore, we questioned what would be the effects of walking on the ground with a BWS system, and its effects if employed in a gait intervention protocol. 


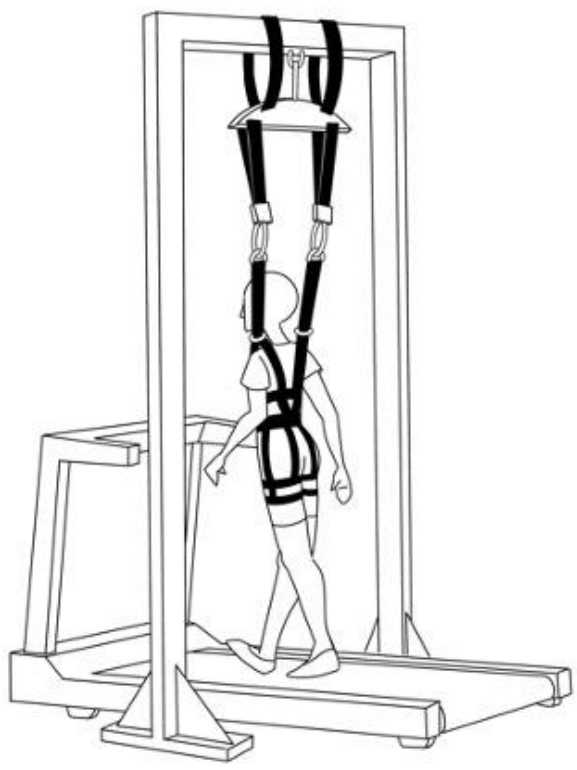

Figure 1. Illustration of a treadmill body weight support system.

Considering the use of a BWS on the ground to implement an alternative strategy for walking performance, our research group first designed a mounting frame that enabled the use of BWS on the ground in the "Laboratório para Estudos do Movimento" (LEM), at UNESP/Rio Claro (Figure 2A); later, a similar system was implemented in the "Laboratório de Análise do Movimento Humano" at UFScar (Figure 2B). Overall, this system contains an electric motor that slides along a metal rail, as the performer walks along the pathway "pulling" this cart by the rail. A load cell connects a horizontal bar to a cable and measures the approximate amount of unloaded body weight, which is shown on a digital display. Several studies were conducted using these BWS systems (Table 1). With the advancement in our investigations considering the overground BWS system, a new version was developed with the assistance of a mechanical engineer (Finix Tecnologia) in the "Laboratório de Análise do Movimento" at Cruzeiro do Sul University (Figure 3). This "new and modern system" contains a suspended rail sustained by steel beans. A moving cart is attached underneath the rail and is controlled by a belt system linked to a servo motor. A customized program (LabView, National Instruments Inc.) is employed to control the displacement, velocity, and acceleration of the moving cart. This moving cart contains a second servo motor that controls the amount of mechanical support throughout the harness attached to a steel bar and belt. As in the previous overground BWS systems, a load cell placed at the bottom of the belt and connected to a digital display provides information regarding the unloaded body weight (Figure 3B). The main studies related to this "updated" new version of the overground BWS system are also presented in Table 1. 
(A)

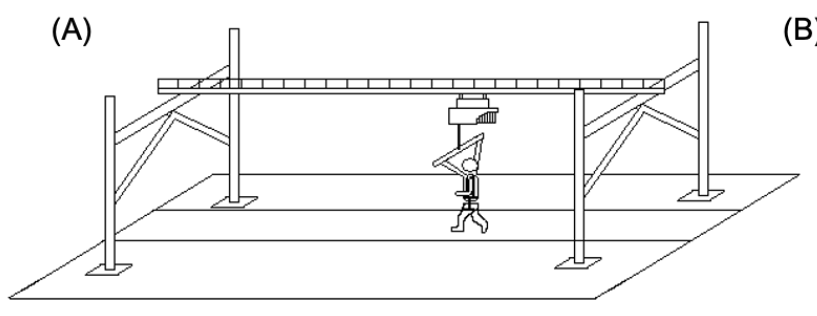

(B)

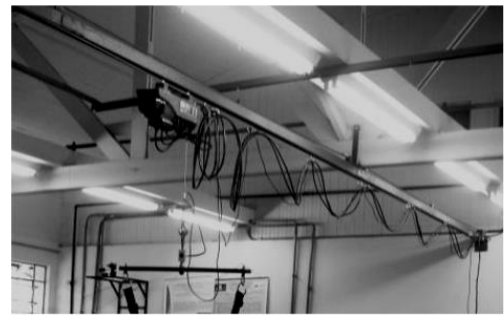

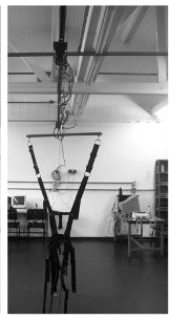

Figure 2. Illustration of the first versions of an overground body weight support system developed by our research group.
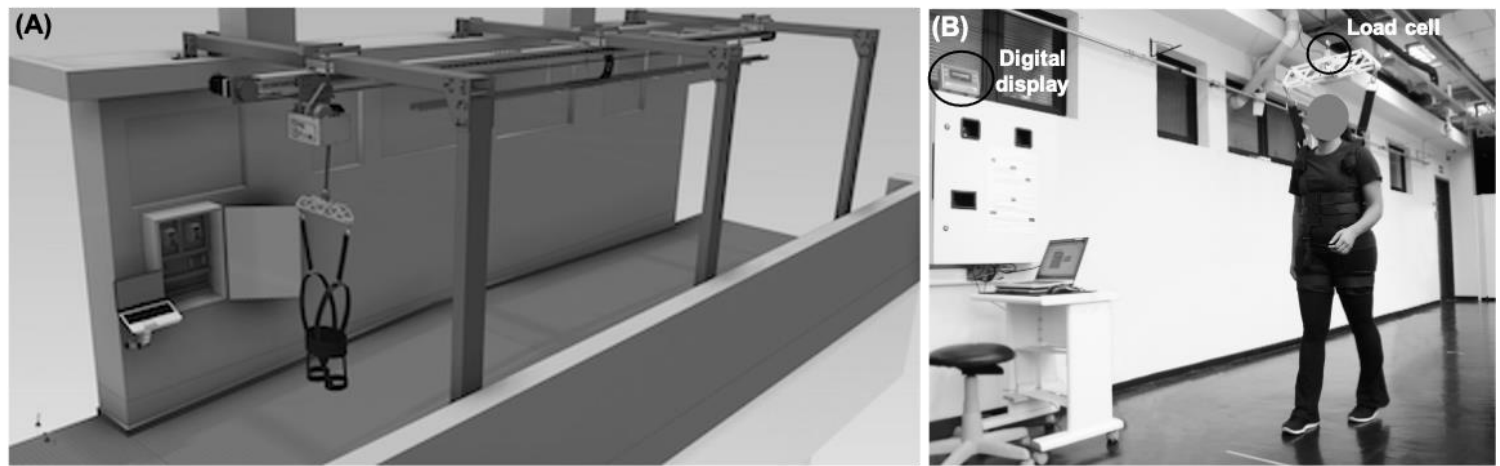

Figure 3. Illustration of an innovative version of an overground body weight support system developed by our research group.

Table 1 - List of the main studies that employed the overground body weight support systems developed by our research group, having non-disabled individuals (left) and individuals with gait impairment (right) as the participants.

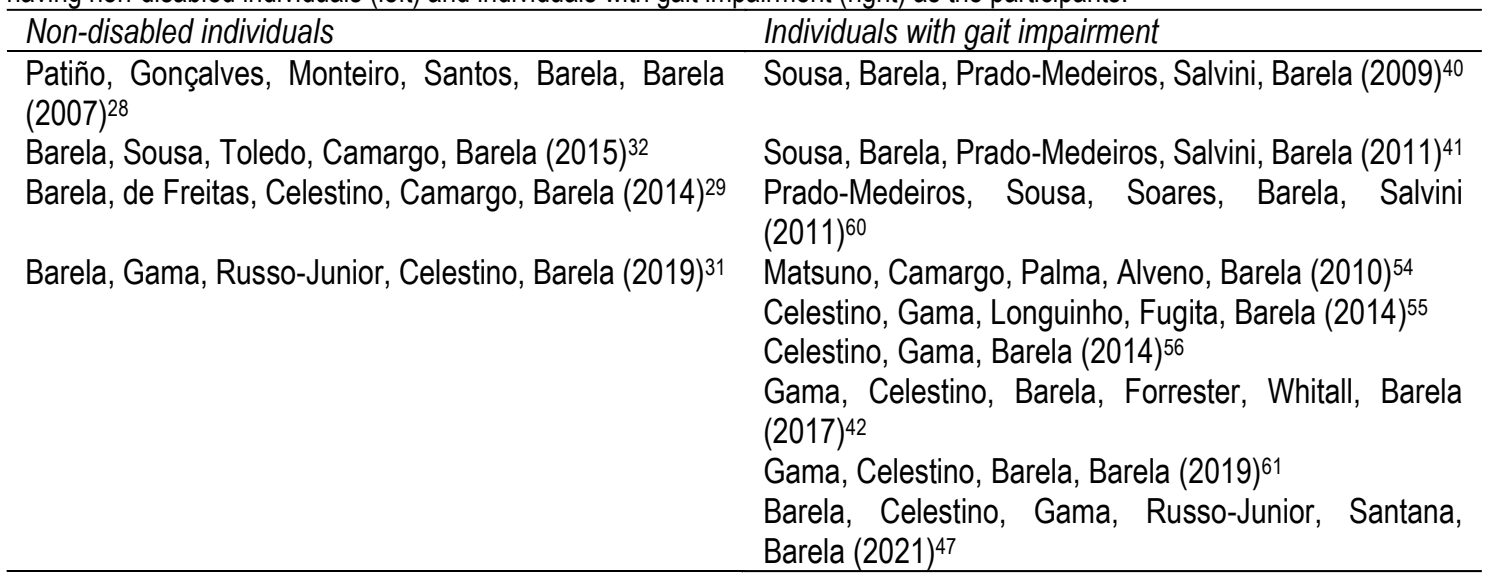

Before considering individuals with gait impairments, our target population, the initial investigations with each of the overground BWS systems were conducted with nondisabled young adults as participants, ${ }^{28,29}$ to uncover and further understand the effects of overground BWS on gait coordination and control. Patiño et al. ${ }^{28}$ investigated young adults walking on the ground with no BWS ("free") and with $0 \%, 10 \%, 20 \%$, and $30 \%$ of BWS; Barela et al. ${ }^{29}$ investigated young adults walking with $0 \%, 15 \%$, and $30 \%$ of BWS. Overall, these studies revealed that non-disabled young adults walk approximately $20 \%$ slower under the BWS system conditions, and in cases where the walking speed is not controlled,28 speed is reduced as body weight unloading increases. The vertical mechanical support imposed by the overground BWS systems also modifies the joint 
excursion of the lower limb, ${ }^{28}$ gradually reducing the magnitude of weight acceptance, ${ }^{29}$ which in turn can contribute to body stabilization during forward progression. These introductory studies using the overground BWS systems revealed that body unloading promotes gait alterations in individuals with no gait impairments; more importantly, the overground BWS is safe and most likely to be employed in individuals with gait impairment.

As it is common to employ a BWS system on a treadmill, we further compared the walking performance of non-disabled young adults with BWS on a treadmill and the ground. ${ }^{30,31}$ Barela et al. ${ }^{32}$ investigated non-disabled young adults walking "freely" (that is, no harness from the BWS system) and with $30 \%$ of BWS on both treadmill and the ground at a self-selected comfortable speed. The participants of this study walked faster and with longer strides on the ground than on the treadmill, and presented a more stable pattern on the ground, as revealed by the shorter double support duration. ${ }^{32}$ Recently, Barela et al. ${ }^{33}$ investigated non-disabled young adults with the updated version (Figure 3), walking with similar and controlled speed on both treadmill and the ground. Based on the previous studies with the same overground BWS system, ${ }^{29}$ participants walked at approximately $80 \%$ of their "free" self-selected comfortable walking speed, with $0 \%, 10 \%$, and $20 \%$ of BWS. Overall, the results of this study revealed that even when controlling the mean walking speed and keeping it similar for both surfaces, non-disabled young adults walked with shorter and slower strides and presented longer double support duration on the treadmill than on the ground. However, this study also revealed that non-disabled young adults presented less variability on the treadmill than on the ground. ${ }^{33}$ Once more, the results of these studies revealed that the overground BWS system promoted a gait pattern more similar to the daily basis than the one observed on a treadmill.

We employed the BWS system for individuals with gait impairments. More specifically, we investigated individuals with stroke and children with cerebral palsy. Although both groups presented gait impairments, they had different characteristics. Therefore, we present these studies separately, as follows.

\section{THE USE OF PARTIAL BWS SYSTEMS IN INDIVIDUALS WITH STROKE}

Stroke is related to a neurological disorder due to a substantial blood flow reduction in one part of the brain, ${ }^{34}$ causing damage to the brain tissue as this reduction prevents oxygen supply. ${ }^{35}$ Consequently, individuals with stroke can present sensory and motor disturbances in the contralateral body side of the brain damage area, which affect daily life activities, such as walking. ${ }^{36}$ Usually, individuals with stroke walk slowly, with short and asymmetrical steps, and the stance period is shorter in the paretic limb compared to the nonparetic limb. ${ }^{37}$

Walking is one of the main aims of an intervention program for individuals with stroke, ${ }^{37}$ and the use of BWS systems on a treadmill is one of the strategies widely employed for gait rehabilitation. ${ }^{38}$ Considering the requirements in terms of propulsion and balance to walk on a treadmill, 39 and the extent of skill transfer to daily life basis, we first evaluated individuals with stroke walking with $0 \%$ and $30 \%$ of BWS on the ground. 40 This preliminary study revealed that these individuals reduced stride length and speed and the excursion of the hip joint compared to ordinary walking, and did not modify the single and double limb support and swing period durations, nor the typical asymmetrical gait pattern. These results suggested that individuals with stroke presented more difficulty walking with 
BWS on the ground than without it, ${ }^{40}$ which could be considered a challenging context for walking practice. Afterwards, these individuals underwent a gait intervention program with the overground BWS system three times per week for 6 weeks. ${ }^{41}$ They were assessed for walking with no BWS system before and after the intervention. Individuals with stroke walked faster, with longer strides and symmetrical steps, increased toe clearance, and lower limb excursion after gait intervention with BWS. Based on these results, it was suggested that the use of an overground BWS system is safe and a favorable strategy for gait rehabilitation in individuals with stroke. ${ }^{41}$

The next investigation was regarding the comparison between a gait intervention program using BWS on a treadmill and on the ground. ${ }^{42}$ In this randomized controlled trial, the participants were randomly assigned to either treadmill or overground gait training with BWS, three times per week, for 6 weeks. They were assessed 1 week before, 1 week after, and 6 weeks after the last training session (follow-up). The assessments included clinical tests (10-meter walk test, ${ }^{43} 6$-minute walk test, ${ }^{44}$ motor domain of functional independent measurement, ${ }^{45}$ and Fugle-Meyer test ${ }^{46}$ ) and walking at a self-selected comfortable speed with no BWS. Overall, all participants improved and maintained their walking speed, resistance, lower limb motor function, and single-limb support duration after the intervention. However, only the participants who underwent overground gait training with BWS improved and maintained the step length of the paretic limb and step length symmetry. Those who underwent treadmill gait training with the BWS protocol improved the paretic limb step length only at follow-up. The results of this study suggest that the overground BWS system may be more useful than the treadmill BWS system. ${ }^{42}$

Based on the results of these previous studies, ${ }^{41,42}$ we conducted a new study comparing the walking surface (that is, treadmill and overground) and different amounts of BWS, while controlling similar walking speeds on both BWS systems ${ }^{47}$ as we previously did with the non-disabled young adults. ${ }^{33}$ Basically, we focused on spatiotemporal changes, variability, and the amount of change between ordinary walking and walking with $0 \%, 10 \%$, and $20 \%$ of BWS on the treadmill and on the ground. Overall, the results of this study indicated that the changes presented by the individuals with stroke were mainly related to the surface than the amount of BWS, with overground walking being more related to ordinary walking. The overground favored longer and faster strides, shorter double support and longer single limb support durations, more variability, and more similarity to ordinary walking compared to the treadmill conditions. Based on the results, Barela et al. ${ }^{47}$ suggested that if the intervention's goal was to maintain consistency, the use of a BWS system on a treadmill was preferable. Conversely, if the intervention's goal is adaptability, the use of a BWS system on the ground should be the choice. In addition, if one is concerned with the skill transfer from training to daily life, the use of an overground BWS system for gait intervention is indicated as it promotes a more generalizable gait training and transfer to day-to-day requirements. ${ }^{47}$

\section{THE USE OF PARTIAL BWS SYSTEMS IN CHILDREN WITH CEREBRAL PALSY}

Cerebral palsy (CP) is a broad term related to a group of permanent disorders in movement and posture development, which are attributed to non-progressive disturbances that occur in the developing fetal or infant brain. ${ }^{48}$ The motor severity, which varies broadly 
among children with $\mathrm{CP}$, is normally classified according to the Gross Motor Function Classification System (GMFCS), ${ }^{49}$ ranging from level I (minimal limitations) to level V (severe limitations). The functional abilities of children with $\mathrm{CP}$ are according to the location and extension of brain lesion, and besides the GMFCS classification, children with $\mathrm{CP}$ are also classified according to their affected limbs (hemiplegia, diplegia, quadriplegia) and muscle tone (spastic, ataxic, athetoid, hypotonic, and mixed type). ${ }^{50,51}$ Based upon these classifications, one can deduce how challengeable it is to investigate gait in children with CP.

Gait improvement or acquisition is one of the major interests of parents and caregivers of children with CP. Although the use of BWS has been a gait intervention strategy for these children, the investigations are still very limited, and most of the investigations have been conducted as case studies. ${ }^{52,53}$ Instead of conducting a gait intervention, we investigated children with $\mathrm{CP}$ walking with BWS on a treadmill and on the ground. $54,55,56$

Initially, we investigated children with CP with mild motor impairment (independent walkers) walking with $0 \%$ and $30 \%$ of BWS on a treadmill and on the ground. ${ }^{54}$ Spatiotemporal parameters and joint angles were compared among the experimental conditions and free walking. This was the first study investigating children with $\mathrm{CP}$ walking with BWS on the ground, and the results revealed that they were able to walk under all experimental conditions. Similar to non-disabled young adults and individuals with stroke, children with CP walked slower, with shorter strides, longer double support, and shorter single support durations on the treadmill than on the ground, indicating better walking performance on the ground compared to the treadmill. ${ }^{54}$

Next, we investigated whether children with more severe motor impairment could walk with $0 \%, 15 \%$, and $30 \%$ of BWS on a treadmill and on the ground. ${ }^{55,56}$ First, we investigated children between 4 and 8 years of age walking at similar speeds in both systems. These children maintained similar cadence and temporal organization (that is, single-and double-limb support, and swing durations) among experimental conditions, though, they walked with longer steps and strides on the ground than on the treadmill. ${ }^{5}$ Although, in this first study, we investigated a small and heterogenic sample of children with $\mathrm{CP}$, it was the first attempt to test the overground BWS system with a servo motor controlled by a computer program, and it was possible to verify that such a system allowed more impaired children to walk under different amounts of body weight unloading. In a subsequent study, ${ }^{56}$ we investigated spatiotemporal parameters and joint angles under the same experimental conditions as the previous one. ${ }^{55}$ Overall, the second study revealed that even the children who could not walk independently were able to walk with a BWS system on a treadmill and on the ground. More importantly, even though we found a high variability among the children who participated in this study, we observed that children with $\mathrm{CP}$ walking with the overground BWS system presented a gait pattern more similar to that presented by typically developing children. ${ }^{56}$

Finally, we conducted a pilot study (unpublished data) with an intervention lasting 6 weeks (3 times/week) with BWS on the ground. After randomization and before the training sessions, all children were assessed using the Gross Motor Function Measures (GMFM), ${ }^{57}$ a scale that is widely used to evaluate children's gross motor skills, with 88 tasks divided into five dimensions (lying and rolling, sitting, crawling and kneeling, standing, and walking, running, and jumping). ${ }^{58}$ We also assessed the children walking on a 7-m 
long walkway with reflective markers attached on specific body landmarks ${ }^{59}$ that defined lower limb segments, using a computerized gait analysis system (VICON, Inc.). All assessments were conducted before, one week after, and one month after the last training session. It is important to note that most of the children who participated in this study were unable to walk independently, and assistance from the experimenters was necessary. Overall, we found that children with CP improved their gross motor function, walking speed, and step length, independent of the training group.

From these pilot studies, we realized that it is possible to conduct gait intervention with both overground and treadmill BWS systems in children with $\mathrm{CP}$, although some extra strategies are necessary to engage them in the training sessions. For example, to motivate children to keep walking and to make the intervention fun for them, and to maintain their good mood and involvement throughout the entire session, we suggest the use of footprints along the pathway as a "target" where they were supposed to step on; recounting a story by making up characters, including ourselves in their "fairy tales"; using songs, dance movements, and liveliness that the therapists were to perform during sessions. An important point is that it is not possible to maintain the same strategies for all children or even for the same child in all training sessions to maintain their motivation, as each child is peculiar and each session is often unique. Taken together, we recommend the use of BWS systems as a strategy for gait intervention in children with CP. We also suggest considering children with severe limitations, and for them, the walking acquisition should not be set as the main goal. Usually, more impaired children stay laying down most of time (not to say all the time) and they do not have the opportunity to stand still. The use of a harness attached to a metal structure enables these children to experience how they feel about standing up and trying to move around, which in turn can improve their trunk control, breathing, and enthusiasm from their parents and caregivers, among other aspects. All these issues are important and should be aimed at in any intervention protocol, especially those involving children with such disability severity.

\section{CONCLUDING REMARKS}

In the past years, we have investigated gait and alternative ways to enable individuals with gait impairment to walk based on the constraints perspective. ${ }^{11}$ Based on our studies, we demonstrate that the use of a BWS system is appropriate for walking practice. The results revealed some of the gait parameters that could be changed according to the surface (that is, treadmill or ground) and the amount of body weight unloading. More importantly, we verified that individuals with severe gait impairment could walk with a BWS system. Specifically, some children with CP had the opportunity to stand up for a longer period of time than they usually could on a daily life basis. Even though it was not possible for us to conduct a clinical trial or a similar investigation, we ensure the excitement of children's caregivers with such a promising strategy that can enable children with CP to stand up and move. The use of a harness attached to a stable and safe structure can offer the opportunity to acquire posture control, progressive force development in the lower limbs, interaction with the environment, and hands free option for the therapists to deal with aspects other than helping with balance.

Certainly, there are still different aspects to investigate the use of BWS systems as a strategy to manipulate the constraints. We hope this paper will trigger the interest of 
professionals and researchers dealing with gait intervention to adopt similar strategies during their practice and investigations.

\section{REFERENCES}

1. Whittle M. Gait analysis: an introduction. 4th ed. Ediburgh: Butterworth Heinemann; 2007.

2. Yaguramki N, Kimura T. Acquirement of stability and mobility in infant gait. Gait Posture. 2002;16:69-77.

3. Devita $P$, Hortobagyi T. Age causes a redistribution of joint torques and powers during gait. J Appl Physiol. 2000;88:1804-1811.

4. Clark JE, Whitall J, Phillips SJ. Human interlimb coordination: the first 6 months of independent walking. Dev Psychobiol. 1988;21:445-456. doi: 10.1002/dev.420210504.

5. Zhang B, Zhang Y, Begg RK. Gait classification in children with cerebral palsy by bayesian approach. Pattern Recognit. 2009;42:581-586.

6. Yogev G, Plotnik M, Peretz C, Giladi N, Hausdorff JM. Gait asymmetry in patients with Parkinson's disease and elderly fallers: when does the bilateral coordination of gait require attention? Exp Brain Res. 2007;177:336-346. doi: 10.1007/s00221-006-0676-3.

7. De Quervain IA, Simon SR, Leurgans S, Pease WS, Mcallister D. Gait pattern in the early recovery period after stroke. J Bone Joint Surg Am. 1996;78:1506-1514. doi: 10.2106/00004623-199610000-00008.

8. Fong DT, Hong Y, Li JX. Lower-extremity gait kinematics on slippery surfaces in construction worksites. Med Sci Sports Exerc. 2005;37:447-454. doi: 00005768200503000-00016 [pii].

9. Yang F, King GA. Dynamic gait stability of treadmill versus overground walking in young adults. J Electromyogr Kinesiol. 2016;31:81-87. doi: 10.1016/j.jelekin.2016.09.004.

10. Barela AMF, Stolf SF, Duarte M. Biomechanics characteristics of adults walking in shallow water and on land. J Electromyogr Kinesiol. 2006;16:250-256.

11. Newell KM. Constraints on the development of coordination. In: Wade MG, Whiting HTA (eds). Motor development in children: aspects of coordination and control. Boston, MA: Martin Nighoff; 1986:pp.341-360.

12. Lovely RG, Gregor RJ, Roy RR, Edgerton VR. Effects of training on the recovery of fullweight-bearing stepping in the adult spinal cat. Exp Neurol. 1986;92:421-435.

13. Barbeau H, Rossignol S. Recovery of locomotion after chronic spinalization in the adult cat. Brain Res. 1987;412:84-95.

14. Barbeau H, Wainberg M, Finch L. Description and application of a system for locomotor rehabilitation. Med Biol Eng Comput. 1987;25:341-344.

15. Finch $L$, Barbeau $H$, Arsenault $B$. Influence of body weight support on normal human gait: development of a gait retraining strategy. Phys Ther. 1991;71:842-855; discussion 855846. 
16. Visintin M, Barbeau H, Korner-Bitensky N, Mayo NE. A new approach to retrain gait in stroke patients through body weight support and treadmill stimulation. Stroke. 1998;29:1122-1128.

17. Frey M, Colombo G, Vaglio M, Bucher R, Jorg M, Riener R. A novel mechatronic body weight support system. IEEE Trans Neural Syst Rehabil Eng. 2006;14:311-321. doi: 10.1109/TNSRE.2006.881556.

18. Barbeau H, Lamontagne A, Ladouceur M, Mercier I, Fung J. Optimizing locomotor function with body weight support training and functional electrical stimulation. In: Latash ML, Levin MF (eds). Progress in motor control: effects of age, disorders, and rehabilitation, vol 2. Champaign, IL: Human Kinetics; 2004:pp.237-251.

19. Hesse S. Locomotor therapy in neurorehabilitation. NeuroRehabilitation. 2001;16:133-139.

20. Mattern-Baxter K. Effects of partial body weight supported treadmill training on children with cerebral palsy. Pediatr Phys Ther. 2009;21:12-22. doi:

10.1097/PEP.0b013e318196ef42.

21. Miyai I, Fujimoto Y, Ueda Y, Yamamoto H, Nozaki S, Saito T, et al. Treadmill training with body weight support: its effect on Parkinson's disease. Arch Phys Med Rehabil. 2000;81:849-852.

22. Schindl MR, Forstner C, Kern H, Hesse S. Treadmill training with partial body weight support in nonambulatory patients with cerebral palsy. Arch Phys Med Rehabil. 2000;81:301-306.

23. Moseley AM, Stark A, Cameron ID, Pollock A. Treadmill training and body weight support for walking after stroke. Cochrane Database of Syst Rev. 2005:CD002840.

24. Terson De Paleville D, Mckay W, Aslan S, Folz R, Sayenko D, Ovechkin A. Locomotor step training with body weight support improves respiratory motor function in individuals with chronic spinal cord injury. Respir Physiol Neurobiol. 2013;189:491-497. doi: 10.1016/j.resp.2013.08.018.

25. Alton F, Baldey L, Caplan S, Morrisey MC. A kinematic comparison of overground and treadmill walking. Clin Biomech. 1998;13:434-440.

26. Warabi T, Kato M, Kiriyama K, Yoshida T, Kobayashi N. Treadmill walking and overground walking of human subjects compared by recording sole-floor reaction force. Neurosci Res. 2005;53:343-348. doi: 10.1016/j.neures.2005.08.005.

27. Lee SJ, Hidler J. Biomechanics of overground versus treadmill walking in healthy individuals. J Appl Physiol. 2008;104:747-755.

28. Patiño MS, Gonçalves AR, Monteiro BC, Santos IL, Barela AMF, Barela JA. Características cinemáticas, cinéticas e eletromiográficas do andar de adultos jovens com e sem suporte parcial de peso corporal. Rev Bras Fisioter. 2007;11:19-25.

29. Barela AM, De Freitas PB, Celestino ML, Camargo MR, Barela JA. Ground reaction forces during level ground walking with body weight unloading. Braz J Phys Ther. 2014;18:572579. doi: 10.1590/bjpt-rbf.2014.0058. 
30. Barela AMF, Toledo DR, Sousa CO, Barela JA. Body weight support system: treadmill versus overground walking. Motor Control. 2007;11:S181-S182.

31. Barela AMF, Gama GL, Russo-Junior DV, Celestino ML, Barela JA. Gait alterations during walking with partial body weight supported on a treadmill and over the ground. Sci Rep. 2019;9:8139. doi: 10.1038/s41598-019-44652-y.

32. Barela AMF, Sousa CO, Toledo DR, Camargo MR, Barela JA. Assessment of nondisabled individuals walking with partial body weight support on a treadmill and over the ground. Braz J Motor Behav. 2015;9:1-10.

33. Barela AMF, Gama GL, Russo-Junior DV, Celestino ML, Barela JA. Gait alterations during walking with partial body weight supported on a treadmill and over the ground. Sci Rep. 2019;9:8139. doi: 10.1038/s41598-019-44652-y.

34. Hossmann KA. Pathophysiology and therapy of experimental stroke. Cell Mol Neurobiol. 2006;26:1057-1083. doi: 10.1007/s10571-006-9008-1.

35. Who. Stroke, cerebrovascular accident, http://www.who.int/topics/cerebrovascular_accident/en/ (2018, accessed February 21st 2018).

36. Wade DT, Hewer RL. Functional abilities after stroke: measurement, natural history and prognosis. J Neurol Neurosurg Psychiatry. 1987;50:177-182. doi: 10.1136/jnnp.50.2.177.

37. Olney SJ, Richards C. Hemiparetic gait following stroke. Part I: Characteristics. Gait Posture. 1996;4:136-148.

38. Hesse S. Treadmill training with partial body weight support after stroke: a review. NeuroRehabilitation. 2008;23:55-65.

39. Harris-Love ML, Forrester LW, Macko RF, Silver KHC, Smith GV. Hemiparetic gait parameters in overground versus treadmill walking. Neurorehabil Neural Repair. 2001;15:105-112.

40. Sousa CO, Barela JA, Prado-Medeiros CL, Salvini TF, Barela AMF. The use of body weight support on ground level: an alternative strategy for gait training of individuals with stroke. J Neuroeng Rehabil. 2009;6:43. doi: 10.1186/1743-0003-6-43.

41. Sousa CO, Barela JA, Prado-Medeiros CL, Salvini TF, Barela AM. Gait training with partial body weight support during overground walking for individuals with chronic stroke: a pilot study. J Neuroeng Rehabil. 2011;8:48. doi: 10.1186/1743-0003-8-48.

42. Gama GL, Celestino ML, Barela JA, Forrester L, Whitall J, Barela AM. Effects of gait training with body weight support on a treadmill versus overground in individuals with stroke. Arch Phys Med Rehabil. 2017;98:748-745. doi: 10.1016/j.apmr.2016.11.022.

43. Bohannon RW, Andrews AW, Thomas MW. Walking speed: reference values and correlates for older adults. J Orthop Sports Phys Ther. 1996;24:86-90. doi: 10.2519/jospt.1996.24.2.86.

44. Laboratories ATSCOPSFCPF. ATS statement: guidelines for the six-minute walk test. Am J Respir Crit Care Med. 2002;166:111-117. doi: 10.1164/ajrccm.166.1.at1102. 
45. Riberto M, Miyazaki MH, Jucá SSH, Sakamoto H, Pinto PPN, Battistella LR. Validação da versão brasileira da Medida de Independência Funcional. Acta Fisiátr. 2004;11:72-76.

46. Maki T, Quagliato EMaB, Cacho EWA, Paz LPS, Nascimento NH, Inoue MMEA, et al. Estudo de confiabilidade da aplicação da escala de Fugl-Meyer no Brasil. Rev Bras Fisioter. 2006;10:177-183.

47. Barela A, Celestino M, Gama G, Russo-Junior D, Santana D, Barela J. Gait alterations induced by unloaded body weight in individuals with stroke while walking on moveable and fixed surfaces. Med Eng Phys. 2021;95:9-14. doi: 10.1016/j.medengphy.2021.07.002.

48. Rosenbaum P, Paneth N, Leviton A, Goldstein M, Bax M. A report: the definition and classification of cerebral palsy April 2006. Dev Med Child Neurol. 2007;49:8-14.

49. Palisano RJ, Rosenbaum P, Bartlett D, Livingston MH. Content validity of the expanded and revised Gross Motor Function Classification System. Dev Med Child Neurol. 2008;50:744-750. doi: 10.1111/j.1469-8749.2008.03089.x.

50. Rosenbaum P, Paneth N, Leviton A, Goldstein M, Bax M, Damiano D, et al. A report: the definition and classification of cerebral palsy April 2006. Dev Med Child Neurol. 2007;109:8-14.

51. Aircardi J, Bax M. Cerebral palsy. In: Aircardi J (ed) Diseases of motor system in childhood. 2nd ed. London: Mac Keith 1998:pp.210-239.

52. Mutlu A, Krosschell K, Spira DG. Treadmill training with partial body-weight support in children with cerebral palsy: a systematic review. Dev Med Child Neurol. 2009;51:268-275. doi: 10.1111/j.1469-8749.2008.03221.x.

53. Apte S, Plooij M, Vallery H. Influence of body weight unloading on human gait characteristics: a systematic review. J Neuroeng Rehabil. 2018;15:53. doi: 10.1186/s12984-018-0380-0.

54. Matsuno VM, Camargo MR, Palma GC, Alveno D, Barela AM. Analysis of partial body weight support during treadmill and overground walking of children with cerebral palsy. Rev Bras Fisioter. 2010;14:404-410. doi: S1413-35552010000500009 [pii].

55. Celestino ML, Gama GL, Longuinho GSC, Fugita M, Barela AMF. Influence of body weight unloading and support surface during walking of children with cerebral palsy. Fisioter Mov. 2014;27:591-599.

56. Celestino ML, Gama GL, Barela AM. Gait characteristics of children with cerebral palsy as they walk with body weight unloading on a treadmill and over the ground. Res Dev Disabil. 2014;35:3624-3631. doi: 10.1016/j.ridd.2014.09.002.

57. Russell DA, Rosenbaum PL, Avery LM, Lane M. Gross motor function measure (GMFM-66 \& GMFM-88) user's manual. London: Mac Keith Press; 2002.

58. Russell D, Rosenbaum P, Cadman D, Gowland C, Hardy S, Jarvis S. The gross motor function measure: a means to evaluate the effects of physical therapy. Dev Med Child Neurol. 1989;31:341-352.

59. Vicon. Vicon plug-in-gait product guide - foundation notes revision 2.0 March 2010. Vicon Motion System. Vicon Motion System Limited, 2010. 
60. Prado-Medeiros CL, Sousa CO, Souza AS, Soares MR, Barela AM, Salvini TF. Effects of the addition of functional electrical stimulation to ground level gait training with body weight support after chronic stroke. Rev Bras Fisioter. 2011;15:436-444.

61. Gama GL, Celestino ML, Barela JA, Barela AMF. Gait initiation and partial body weight unloading for functional improvement in post-stroke individuals. Gait Posture. 2019;68:305310. doi: 10.1016/j.gaitpost.2018.12.008.

\section{ACKNOWLEDGMENTS}

The authors would like to thank all the co-authors of the studies presented in Table 1.

Citation: Barela AMF, Gama GL, Celestino ML. (2021). Constraint manipulation as a feasible strategy for gait alteration and intervention: a scoping review. Brazilian Journal of Motor Behavior, 15(5):416-428.

Editors: Dr Fabio Augusto Barbieri - São Paulo State University (UNESP), Bauru, SP, Brazil; Dr José Angelo Barela São Paulo State University (UNESP), Rio Claro, SP, Brazil; Dr Natalia Madalena Rinaldi - Federal University of Espírito Santo (UFES), Vitória, ES, Brazil.

Copyright:@ 2021 Barela, Gama and Celestino and BJMB. This is an open-access article distributed under the terms of the Creative Commons Attribution-Non Commercial-No Derivatives 4.0 International License which permits unrestricted use, distribution, and reproduction in any medium, provided the original author and source are credited.

Funding: This work was supported by the São Paulo Research Foundation - FAPESP [Grant Numbers 2010/15218-3, 2013/02322-5, and 2015/25376-9 to AMFB, and fellowship numbers 2013/01050-1 to GLG, 2015/13100-0 and 2016/23571-1 to MLC].

Competing interests: The authors have declared that no competing interests exist.

DOl: https://doi.org/10.20338/bjmb.v15i5.263 